\title{
Salmonella Fecal Excretion Control in Broiler Chickens by Organic Acids and Essential Oils Blend Feed Added
}

Technical Note

\section{-Author(s)}

Borsoi $A^{1}$

Santos $L^{3}$

Diniz GS

C. Salle CTP2

Moraes $\mathrm{HLS}^{2}$

Nascimento VP2

Tuiuti University of Paraná. Veterinary Medicine - FCBS.

2 Centre for Diagnostics and Research in Avian Pathology, Faculty of Veterinary Medicine, Federal University of Rio Grande do Sul.

3 Faculty of Agronomy and Veterinary Medicine, University of Passo Fundo. Campus I.

4 Laboratory of Parasitary Disease, Londrina State University.

\section{-Mail Adress}

\section{A Borsoi}

Secretaria da Coordenação - Veterinária

Rua Sydnei Rangel dos Santos, 238

Santo Inácio

82010-330. Curitiba, Paraná, Brazil.

Tel.: +55 (41) 33317868

E-mail: anderliseb@yahoo.com.br

\section{Eeywords}

Broiler chicks, organic acids, Salmonella Enteritidis.

\begin{abstract}
Salmonellosis is an important disease with economic impact as it may affect animal performance and may result in foodborne disease in humans through the eggs and carcass contamination. Regarding the Salmonella control, it is possible to decrease its fecal excretion and the contamination of chicken carcasses by adding organic acids to the feed or drinking water at appropriate times. The aim of this study was to test a blend of organic acids and essential oils in broilers challenged with Salmonella Enteritidis (SE), and to verify the fecal excretion of Salmonella. Sixty broilers were placed in four groups. One group was the negative control. Another group was orally inoculated at 1 day-old with $10^{5} \mathrm{CFU} / \mathrm{mL}$ of SE as a positive SE control. Two groups (T3 and T4) were orally inoculated at 1 day-old with $10^{5} \mathrm{CFU} / \mathrm{mL}$ of SE and their feed was separately treated with 0.5 and $1 \%$ of organic acids and essential oils, respectively. To assess the fecal excretion of SE, cloacal swabs were collected from all birds at 2, 6, 13 and 20 days after inoculation. The T3 and T4 groups showed a reduction in fecal excretion of SE at 6 and 20 days after inoculation.
\end{abstract}

\section{INTRODUCTION}

The incidence of food poisoning caused by Salmonella spp. has been increasing around the world despite technological advances in food production and the adoption of better hygiene measures. Foods of animal origin, such as chicken meat, eggs and derivates, continue to be a major cause of poisoning. Contaminated chickens become intestinal carriers, shedding the microorganism through their feces for long periods of time. Contaminated chickens thus end up introducing the bacteria into slaughterhouses (Andreatti Filho et al., 2000). Avian salmonellosis, when not caused by Salmonella Pullorum and Salmonella Gallinarum, is named paratyphoid infection, and may be caused by different Salmonella serovars. This disease has an important economic impact as it may affect animal performance and cause morbidity and mortality in younger birds. In addition, paratyphoid salmonellosis may result in foodborne disease in humans due to its ability to colonize the digestive tract of chickens, resulting in carcass contamination (Oliveira et al., 2000). Regarding the control of Salmonella, it is possible to decrease its fecal shedding and the contamination of chicken carcasses and eggs by adding organic acids to the feed or drinking water at appropriate times. The basic principle behind the mode of action of organic acids on bacteria is that undissociated (non-ionized) organic acids can penetrate the bacterial cell wall and disrupt the normal physiology of certain types of "pH-sensitive" bacteria (which cannot tolerate large internal and external $\mathrm{pH}$ variations), such as Escherichia coli, Salmonella spp., Clostridium perfringes, Listeria monocytogenes, 
and Campylobacter spp (Gauthier, 2005; Van Immerseel et al., 2006). The relative efficiency of the different organic acids varies according to their source, as a result of their different pK potential, and all acids are more effective at a low pH. It is often accepted that organic acids enhance the action of others acids. Organic acids and essential oils can be combined because there appears to be a synergistic interaction between them. Some authors suggest that essential oils also act by damaging the bacterial cell membrane, thus facilitating the penetration of organic acids into the bacterial cytoplasm (Le Ny, 2005).

The aim of this study was to test a blend of organic acids and essential oils in broilers orally challenged with Salmonella Enteritidis and to verify its efficiency in reducing the fecal shedding of Salmonella.

\section{MATERIALS AND METHODS}

\section{Birds}

Sixty one-day-old male Salmonella-free Ross chicks, hatched from breeders not vaccinated against Salmonellae, were housed in four battery cages. The birds received feed and water ad libitum and the room temperature was adjusted to keep them under thermal comfort.

\section{Bacteria}

Salmonella Enteritidis ATCC 1980 (SE) was kindly provided by Dr. Paul Barrow (AFRC Institute for Animal Health, Berkshire, UK). The strain was retrieved from freeze-dried cultures and cultured overnight on brain heart infusion broth (BHI; Merck) at $37^{\circ} \mathrm{C}$. The culture was then streaked onto xylose lysine deoxycholate agar (XLD, Difco) and incubated at $37^{\circ} \mathrm{C}$ for 24 hours. One colony was selected and transferred to $\mathrm{BHI}$ broth and incubated at $37^{\circ} \mathrm{C}$ for 2 hours. The colony forming units (CFU) were determined by tenfold dilutions in buffered peptone water $0.1 \%$ (BPW, Oxoid) and streaked onto XLD agar. The suspension with $10^{5} \mathrm{CFU}$ was selected for inoculation.

\section{Feed with addition of organic acids and essential oils blend}

All feeds consisted of corn, soybean meal and soybean oil. The components of the feed formulas are shown in Table 1. Both T3 and T4 groups were fed the blend of organic acids and essential oils (butyric, propionic, lactic and formic acids; and thymol, carvacrol, citrol, cinnamon and clove oils) at $500 \mathrm{~g} / \mathrm{ton}$ and $1,000 \mathrm{~g} / \mathrm{ton}$, respectively, at the expense of starch at the levels of 0.05 and $0.1 \%$ in the feed.

\section{Experimental design}

A completely randomized experimental design with four treatments and 15 replicates each (each bird was a replicate) was applied. Group T1, was inoculated with saline solution, and considered as negative control group; group T2 (inoculated at 1 day of age with $10^{5} \mathrm{CFU} / \mathrm{mL}$ of SE) was not fed organic acids and essential oils was used as control for Salmonella shedding. Group T2 was orally inoculated on day 1 with $10^{5} \mathrm{CFU} / \mathrm{mL}$ of SE and was used as an untreated positive SE control. The two other groups (T3 and T4) were orally inoculated at pne day of age with $10^{5} \mathrm{CFU} /$ $\mathrm{mL}$ of SE and their feed was separately supplemented with 0.5 and $1 \%$ of organic acids and essential oils, respectively. On post-inoculation day 17 , organic acids and essential oils were withdrawn from the feeds of groups T3 and T4. All birds were identified by a wingweb bended metal ring with an individual number. Before inoculation, cloacal swabs were collected from

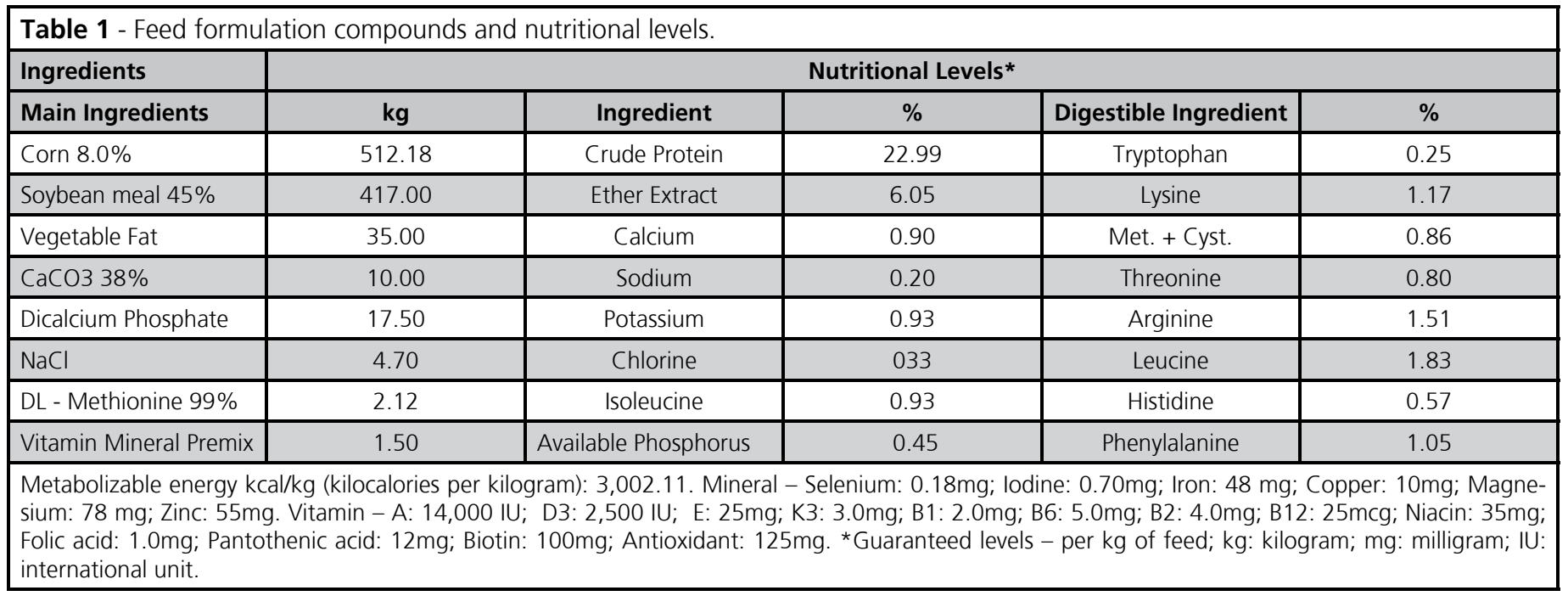


all birds for bacteriological examination in order to check for the absence of Salmonella. Fecal shedding of SE was evaluated by collecting cloacal swabs from all birds on post-inoculation days 2, 6, 13 and 20 . The experiment was approved by the Research Ethics Committee of the School of Veterinary Medicine of Universidade Federal do Paraná, Brazil.

\section{Bacterial isolation and identification}

The cloacal swabs were directly inoculated onto $\mathrm{XLD}$ agar and pre-enriched at $37^{\circ} \mathrm{C}$ for 1 hour in 2 $\mathrm{mL} \mathrm{BPW}$ at $2 \%$. BPW cultures were diluted tenfold in BPW at $0.1 \%$ to $10^{-3}$ and then plated in duplicate XLD agar (adapted from Desmidt et al., 1998). Salmonella colonies were counted and the results were expressed according to the Plate Count Proceedings established in Normative Instruction n. 6, published on August 26, 2003, by the Brazilian Ministry of Agriculture, Livestock and Food Supply (BRASIL, 2003). One Salmonella typical colony per plate was biochemically and antigenically confirmed as SE.

\section{Statistical Analysis}

Colony count data were transformed into log base 10 and were analyzed by ANOVA, and those with statistical differences were submitted to the Tukey's test at the $0.05 \%$ level using Statview for Windows 5.0 (SAS Institute Inc., Cary, NC, USA).

\section{RESULTS}

No difference was observed between the treatment groups on post-inoculation day 6 . However, SE fecal shedding was lower in both groups fed organic acids and essential among at 2 days and at 13 to 20 days, respectively (Table 2 ). There were significant differences T2, T3, and T4 treatment groups, but no difference between groups $\mathrm{T3}$ and $\mathrm{T4}$, indicating the absence of a dose-dependent effect.

\section{DISCUSSION}

The organic acids that are associated with specific antimicrobial activity are short-chain acids, with one to seven carbons, and are either simple monocarboxylic acids, such as formic, acetic, propionic and butyric acids, or carboxylic acids bearing a hydroxyl group (usually on the carbon), such as lactic, malic, tartaric, and citric acids (Dibner \& Buttin, 2002). Acids change microbial populations according to their antimicrobial activity. The mode of action of organic acids on bacteria in pigs and poultry involves the entry of these acids into the bacterial cell in an undissociated form, causing bacterial membrane disruption and inhibition of essential metabolic reactions. The stress on intracellular $\mathrm{pH}$ homeostasis causes the accumulation of toxic anions and the bacteria cannot tolerate large internal and external pH variations. Differently from organic acids, it is difficult to make generalizations about the mode of action of essential oils on bacteria, because each essential oil has different properties and because sensitivity differs across microorganisms. There is a consensus that the mode of action of essential oils on bacteria is related to the impairment of enzyme systems, mainly those involved in energy production and in the synthesis of structural components. Some of the essential oils utilized include cinnamaldehyde, thymol, carvacrol, eugenol, thyme, bay leaf, and clove bud. Organic acids and essential oils can be used in combination, and it has been suggested that they damage the bacterial cell membrane, thus facilitating the penetration of organic acids (Gauthier, 2005). In the present study, the blend of organic acids and essential oils was used in two doses from the first day after hatching. The cloacal swabs on post-inoculation day 2 showed that the control group was negative for Salmonella excretion and that the T3 and T4 groups were shedding SE (Table 2). Some explanations for the SE shedding in these groups may reside firstly in

Table 2 - Salmonella shedding by broiler chicks between 1 and 20 days of age. T2: SE-shedding control, not fed organic acids and essential oils; T3: $0.05 \%$ organic and essential oils, and T4: $0.1 \%$ organic and essential oils, respectively. Results expressed in log ${ }^{10}$.

\begin{tabular}{|c|c|c|c|c|}
\hline Groups & 2 pid (CFU/mL) & 6 pid (CFU/mL) & 13 pid (CFU/mL) & 20 pid (CFU/mL) \\
\hline T1 & - & - & - & - \\
\hline T2 & $0.000 \pm 0.000 b^{*}$ & $0.679 \pm 1.408$ & $1.789 \pm 1.250 \mathrm{a}$ & $2.919 \pm 0.507 \mathrm{a}$ \\
\hline T3 & $0.047 \pm 0.180$ & $0.103 \pm 0.399$ & $0.000 \pm 0.000 \mathrm{~b}$ & $0.968 \pm 1.445 \mathrm{~b}$ \\
\hline T4 & $0.558 \pm 1.210 \mathrm{a}$ & $0.661 \pm 0.661$ & $0.000 \pm 0.000 \mathrm{~b}$ & $0.758 \pm 1.306 \mathrm{~b}$ \\
\hline P values & 0.036 & 0.311 & 0.000 & 0.0001 \\
\hline
\end{tabular}

*Different letters on the same column indicate statistical significance by the test of Tukey test at $95 \%$ confidence interval; pid: post-inoculation day. T1: negative control; T2: Salmonella Enteritidis (SE) shedding control, not fed organic acids and essential oils; T3: $0.5 \%$ organic acids and essential oils added to the feed and T4: $1 \%$ organic acids and essential oils added to the feed. CFU/mL: colony forming units per milliliter of BPW solution.. 
the ability of Salmonella to sense the environmental conditions and some specific conditions that are required to promote adhesion and invasion; secondly, it could be due the capacity of organic acids to specifically alter the expression of the HilA gene (Lawahon et al., 2002; Van Immerseel et al., 2003; Van Immerseel et al., 2004). By doing that, organic acids and essential oils may have changed the environmental conditions (oxygen tension or osmolarity, for example) or may even have affected the expression of some genes that are necessary for bacterial adhesion and invasiveness due to the fact that the feed was given shortly after the chicks were inoculated. All birds were inoculated with the same bacterial suspension and at the same time. In the T2 group, fecal shedding of Salmonella increased from post-inoculation day 6 to the end of the trial. On the other hand, on post-inoculation day 13, the T3 and T4 groups yielded SE-negative swab samples. On day 20, however, T3 and T4 groups were shedding SE again, and this could be caused by the fact that the feeds were changed and organic acids and essential oils were withdrawn from the feeds after post-inoculation day 17 in groups T3 and T4. This was also observed in a trial with broilers given acidified drinking water during the preslaughter period in order to reduce Salmonella in the crop. When water intake was reduced during the preslaughter feed withdrawal period, the consequent reduction in acid intake resulted in an increase in the number of viable SE in the crop (Avila et al., 2003). Oliveira et al., (2000) showed that organic acids added to the feed were not able to prevent infection of birds with S. Enteritidis, S. Agona, S. Infantis and S. Typhimurium serovars, but Berchieri Jr. and Barrow (1996) observed a remarkable reduction in mortality caused by Salmonella gallinarum, affecting the rate of infection between infected and uninfected birds. The results of the use of organic acids and/ or essential oils for Salmonella control may depend upon the Salmonella serovar used as a challenge organism (Oliveira et al., 2000; Santurio et al., 2007). Bacteriological examination of cloacal swabs and litter samples could be negative while the animals can carry Salmonella in their tissues and excrete it intermittently under certain stress conditions (Duchet-Suchaux et al., 1997).

\section{CONCLUSIONS}

The results showed that organic acids and essential oils should be constantly fed to Salmonellacontaminated birds and that their withdrawal from the feed can cause birds to return shedding the bacterium. The present study was able to show that this organic acids and essential oils blend were useful in controlling the fecal shedding of Salmonella Enteritidis from infected chicks and this procedure can be important as part of a Salmonella control program.

\section{REFERENCES}

Avila LAF, Nascimento VP, Canal CW, Salle CTP, Moraes HLS. Effect of acidified drinking water on the recovery of Salmonella Enteritidis from broiler crops. Brazilian Journal of Poultry Science 2003; 5:183-188

Andreatti Filho RL, Silva EN, Ribeiro AR, Kondo N, Curi, PR. Use of anaerobic cecal microflora, lactose and acetic acid for the protection of broiler chicks against experimental infection with Salmonella Typhimurium and Salmonella Enteritidis. Brazilian Journal of Microbiology 2000; 31:107-112.

Berchieri Jr A, Barrow PA. Reduction in incidence of experimental fowl typhoid by incorporation of a commercial formic acid preparation into poultry feed. Poultry Science 1996; 75:339-441.

Brasil. Ministério da Agricultura, Abastecimento e Pecuária. Instrução normativa, SDA No 62, de 26 agosto de 2003. Diário Oficial da União, 18 set. 2003; Seção 1, p.14.

Desmidt M, Ducatelle R, Haesebrouck F. Serological and bacteriological observations on experimental infection with Salmonella Hadar in chickens. Veterinary Microbiology 1998; 60:259-269.

Dibner JJ, Buttin P. Use of organic acids as a model to study the impact of gut microflora on nutrition and metabolism. Journal Applied Poultry Research 2002; 11:453-463.

Duchet-Suchaux M, Lechopier P, Marly J, Bernardete P, Delaunay $R$, Pardon P. Differences in frequency, level and duration of cecal carriage between four outbreed chicken lines infected orally with Salmonella Enteritidis. Avian Disease 1997; 41:559-567.

Gauthier R. Organic acids and essential oils, a realistic alternative to antibiotic growth promoters in poultry [cited 2008 sep.]. Available from: http://www.jefo.ca/pdf/avicola/AnaisAveExpo-R.Gauthier. pdf.

Lawhon SD, Maurer R, Suyemoto M, Altier C. Intestinal short fatty acids alter Salmonella Typhimurium invasion gene expression and virulence through BarA/SirA. Molecular Microbiology 2002; 46:1451-1464.

Le Ny P. Organic acids in poultry production. Mode of action and application [cited 2008 may]. Available from: http://www.jefo.ca/ pdf/avicola/AnaisAveExpo-P.Le\%20Ny.pdf .

Oliveira GH, Berchieri Jr A, Barrow PA. Prevention of Salmonella infection contact using intestinal flora of adult birds and/or a mixture of organic acids. Brazilian Journal of Microbiology 2000; 31:116-120 
Santurio JM, Santurio DF, Pozzatti P, Moraes C, Franchin PR, Alves $\mathrm{SH}$. Atividade antimicrobiana dos óleos essenciais de orégano, tomilho e canela frente a sorovares de Salmonella entérica de origem avícola. Ciência Rural 2007; 37:803-808.

Van Immerseel F, Cawerts K, Devriese LA, Haesebrouck F, Ducatelle R. Feed additives to control Salmonella in poultry. World's Poultry Science Journal 2002; 58:501-509.

Van Immerseel F, De Buck J, Pasmans F, Velge P, Bottreau E, Fievez $V$, Haesebrouck F, Ducatelle R. Invasion of Salmonella Enteritidis in avian intestinal epithelial cells in vitro is influenced by short-chain fatty acids. International Journal of Food Microbiology 2003; 85: 237-248.

Van Immerseel F, De Buck J, Boyen F, Bohez L, Pasmans F, Volf J, Sevcik M, Rychlik I, Haesebrouck F, Ducatelle R. Medium-chain fatty acids decrease colonization and invasion through hilA suppression shortly after infection of chickens with Salmonella enterica serovar Enteritidis. Applied Environmental Microbiology 2004; 3582-3587. 